\title{
Using email interviews in qualitative educational research: Creating space to think and time to talk
}

\begin{abstract}
The paper explores how the Internet and email offers space for participants to think and make sense of their experiences in the qualitative research encounter. It draws on a research study that used email interviewing to generate online narratives to understand academic lives and identities through research encounters in virtual space. The paper discusses how the asynchronous nature of email helps to facilitate this by allowing research participants to contribute to research in their space and according to their own preference in time, and engage in a process of reflection and interaction. However, it also argues for the construction of more collaborative approaches to research that acknowledge their right to use the temporal nature of space and time that email offers to construct, reflect upon and learn from their stories of experience in their own manner, and not merely to the researcher's agenda. It concludes by recognising the importance of email as a research tool for capturing the complexity of social interaction online.
\end{abstract}

Keywords: asynchronous, collaborative, email, narratives, online, space, time 


\section{Introduction}

There is now a rich literature in the social sciences concerning how the Internet has become a site where the social interactions of individuals and communities can be researched and where the construction of practices, meanings and identities can be investigated, including the relationships between researchers and participants, in ways that may not be possible in the physical world (James and Busher 2009). New information and communication technologies (ICTs) and the internet in particular have influenced the dynamics of everyday life, as they 'affect and change time, people's perceptions of time, and the way time is organised' (Lee and Liebenau, 2000, p. 44). Wider social research has explored the use of digital/Internet methods for conducting research on particular topics or groups online as well as discussions on how the Internet has created sites of social interactions for individuals and communities where practices, meanings and identities are constructed (see for example Madge and O'Connor, 2005; Hine, 2005; Murthy, 2008; Ison, 2009; Beneito-Montagut, 2011).At the same time, such studies have highlighted the interrelations between online space and offline contexts (Orgad, 2006) and the ways in which people's spaces increasingly use face-to-face and online communications as part of their daily lives, the 'here and now' of everyday life in a particular space and time interacts ever more easily with the 'there and now' of the other in time and space (Zhao, 2006, James and Busher, 2013).

.Compared with wider social research, qualitative educational research has been relatively slow in its use of online research methods, achieving significantly less applicability in educational contexts as a tool for collecting participant-generated
Comment [nrj71]: The

introduction has been rewritten to clarify and situate the article. The paper is contributing to the body of literature in qualitative educational research where online research has had limited applicability in

educational contexts.

I have made reference to the wider literature in the social sciences where online qualitative research has become widely used, but then linked this to the lack of take up of online research in qualitative

educational research 
reflective qualitative data (Hasim, De Luca, and Bell, 2011). Notable exceptions are Eichhorn's (2001) ethnographic study of a community of young people who selfproduced and disseminated magazines or pamphlets; Hinchcliffe and Gavin's (2008) use of instant messenger software to conduct interviews in educational contexts and Adams and Thompson's (2011) study which used educational technology as research participants and generated rules to 'interviewing' objects. Further, Davies's (2011) research explores the (co)production of online spaces and textual or visual selves on the Internet as part of her work in digital literacy. These studies have demonstrated how Internet spaces, like 'real world' spaces, are jointly constructed and interpreted out of a constant and complex interplay between the real and virtual world (Harricharan and Bhopal, 2014). This paper contributes to this body of literature by exploring how on-going, reflective, qualitative data was collected using email interviews to better understand academics' lives and identities (James 2003, 2007). Using this study, the paper will discuss how the temporal dimensions of email allows individuals to construct, share and understand personal meanings online and offline when it is not always possible to meet face-to-face or be onsite for research purposes because of the constraints of time and space. The paper will also show how email can provide a site to conduct interviews that are enriched by participants' critical reflections of their experiences and iterative engagement with their stories and perspectives.

The paper is divided into three sections. Firstly, it outlines the reasons for choosing email as a method to interview academics. Secondly, by incorporating a number of email narratives into the paper, it discusses the benefits and challenges of email interviewing that result from the fact that academics are able to contribute to research in 
their own time and space. These include the following: 1) how email as an asynchronous virtual 'space' can provide a powerful medium of communication and reflection within the research encounter; 2) how email provides a site for online/offline communications; 3) the importance of the construction of online collaborative approaches to research that both empower and acknowledge the right of academics to use this space in their own manner, and not merely to the researcher's agenda. Finally, the paper concludes by arguing that email not only offers time and space for academics to construct, reflect upon and learn from their stories of experience, but it is an important tool for capturing the complexity of online social interaction.

\section{Research design: Using email to construct academic narratives}

The research discussed in this paper is based on an ethnographic study that sought to examine and understand how 20 senior psychology academics, all in post 1992 higher education institutions across the UK, constructed their careers and identities, both institutionally and individually, and the discourses this gave rise to. More specifically, the focus was on the academics recalling and reliving experience and involved them (re) constructing their academic lives, where issues of time, space and control remained central. Adopting this approach needed a research design and medium of data collection that would allow the academics to tell and reflect on their stories of experience, and for the researchers to explore the participants' understandings of their stories. The research design also called for a site for narrative production that could adequately capture and reflect academics' accounts of how they saw themselves, with a view to revealing some 
of the fundamental structures of their experience (James 2003; 2007). As noted by Taylor $(1989,52):$

the philosophic concern with life as narrative involves an emphasis on dialogue, conversation, story and the processes of inquiry and reflection on experience that allow the individual to identify what has personal significance and meaning for him or her personally.

Using narrative then is much more than "...look for and hear story... Narrative inquiry in the field is a form of living, a way of life..." (Clandinin and Connelly 2000, 78). Following these principles, a number of different narrative methods have been developed that focus on the particularities of experience. These include autobiographical and biographical writing, journal records and field notes of the shared experience through participant observation, as well as interviewing.

The literature has clearly documented how face-to-face qualitative interviews can become a site for narrative production and provide a way of understanding and representing experience (Clandinin and Connelly 2000; Czarnaskia 2004; Hardey, 2004). In designing the research, we considered the suitability of different types of qualitative interviews in terms of design and ethics. Face-to-face interviews can provide rich and in depth stories of experience, and help researchers to gain an understanding of how people construct their lives and the stories they tell about them. It offered us a template with its processes of gaining consent and confidentiality as well as the flexibility to gather data through the use of open questions and follow-up discussion. However, our participants were located at a distance from us within and outside the UK. So we had to overcome the practical constraints (for example costs associated with travel, venue, data transcription) of 
conducting the interviews necessary for our studies. To overcome some of these issues, telephone interviewing as an alternative approach was considered to access the hard-toreach participants. Despite the costs that are saved by using telephone interviews when compared with face-to-face interviewing, because of the absence of travel, a key issue for us was the quality and depth of data that we would collect. As with email, there is an absence of visual cues via telephone due to the loss of contextual and nonverbal data, which can compromise rapport, probing, and interpretation of responses. However, the asynchronous nature of email seemed to offer a solution - to follow up on questions and fully complete interviews in ways that the more immediate, and often one shot nature of face-to-face and telephone interviews could not do (McCoyd and Kerson, 2006). On a practical level, it also would allow us to access the hard-to-reach academics, saving on time and travel. Considering the recruitment process of email interviewing, the possibility for the academics to participate from their own space also seemed to lower the barrier for joining a research project. In this sense the Internet and the use of email helped to diminish the importance of time-frames generally accepted as appropriate for performing a given activity (Tsatou, 2009). This weakening of time constraints, in terms of communication between places difficult to access, and within the working lives of the academics, offered them a new virtual reality that allowed experiences to be experienced. They were not bound by oral communication and physical travel, but could cross and adjust temporal and spatial distances because of the use of electronic media and communications. Further, geographically dispersed academics, were no longer isolated from the context and traditions in which they belonged, providing a "bounded space" within which it was possible to explore how they lived and worked (Henkel 2000) in a 
variety of different macro-cultures and to move back and forth through their narratives, thinking about their responses, drafting and redrafting what they want to write.

Even when the social space within which email as a contemporary communication form creates opportunities for research (Burns 2010, online), it is possible to collect data both online and offline. As noted by Hallett and Barber (2013), understanding contemporary cultures requires acknowledging, respecting, and studying the multiple overlapping spaces where people spend time. As we will see later in the paper, this opened up possibilities to study the interactions of academics in both online and offline spaces to document their personal, and professional interactions recognizing the multi-sited nature of their lives.

The researchers then were interested to explore whether email interviewing could be recognised as a legitimate methodology in the study of academic lives; how it could be used to generate narratives and stories of their experiences in their voice, as well as meet their needs as research participants and become a central place to document how they lived out their academic lives. As we already had access to the academics' email addresses we used them to gain their consent to take part in the study. Consequently, they were invited via email to take part in the research study and to share how they saw themselves within the communities in which they lived and worked. However, the success of the email study depended heavily on how the researchers constructed the virtual research environment in order to engage the academics in the interviews. Implicit 
in this was ensuring that they trusted us and felt safe enough to be able to discuss freely their experiences and feelings.

It was critical that our participants felt confident that their privacy would be adequately protected 'in their eyes' if they self-disclosed, and the risk of harm to them or their communities minimised to a level acceptable to them (Author and Author 2006). To achieve this, the academics were made to feel safe in disclosing their views by emphasizing their anonymity, for example by assuring them that all implicit and explicit links between their names and the data they provided would be removed. We also ensured the academics fully understood how the email interviews would be conducted. Guidelines were therefore sent to them explaining how the study would be carried out online (see also Meho 2006), and more specifically, how they would receive the interview questions (one-by-one embedded in the email message) so that they could focus on that question, rather than be distracted by others, as well as deadlines for responses initially 2-3 days which, as we will see later in the paper, was unrealistic.

\section{'Space' in email interviews? Reflecting on the self}

Bowker and Tuffin $(2004,320)$ suggest that "[s]ituating discourse within a familiar physical location may enhance participants' disclosure, and, hence, the richness of the data gathered." The academics viewed email as disrupting notions of what constitutes academic work and what it means (or what it should mean) to be an academic. This view links to the concept of 'time-space compression' that describes the acceleration of our experience of time and space in which the internet and email have essentially reduced the distances between people and places thus resulting in 'time-space compression'.(Tang, 
2010). It has therefore become easier to move information across space; speeding-up the pace of life while abolishing traditional spatial barriers (for a more detailed discussion see Harvey, 1989). Massey (1994, p.62) has argued that time-space compression never affects all people and places equally; rather, "The ways in which people are inserted into and place within this 'time-space compression' are highly complicated and extremely varied." Time and space is always saturated with relations of power and inequality, and as such, time-space compression for some individuals may be time-space expansion for others (Thrift, 1994). For the study, using email facitiliated the academics' participation in it, and its asynchronicity gave them flexibility to construct narratives at a pace which suited them, unlike the constrained time and space they might have experienced in a faceto-face or telephonic interview. However, the various responsibilities and relationships of the academics' 'meatspace,' often meant that they did not always respond to the research questions, or deliberately chose to ignore the email to create time and space to think. As the academic below reflected: there is so much going on: .

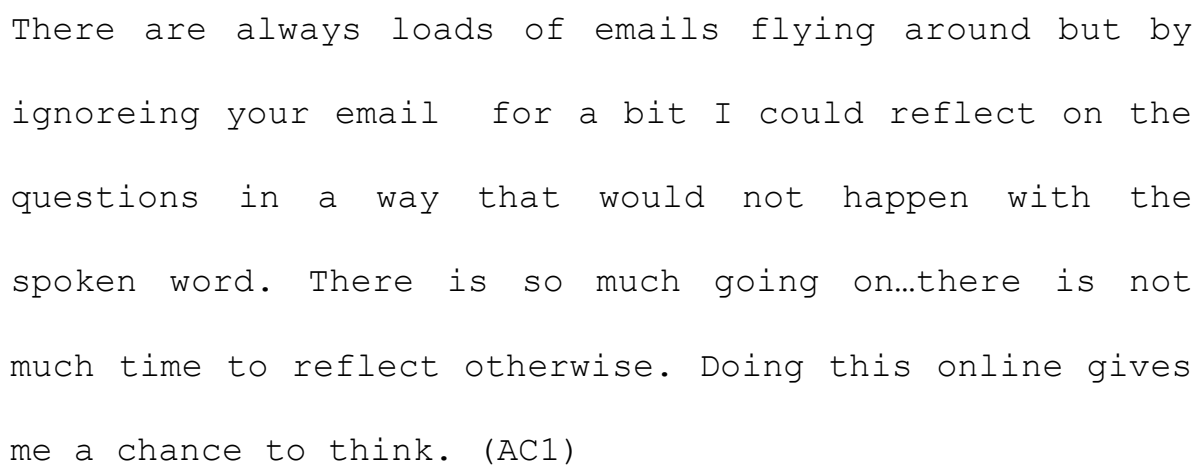


The compression of time-space also meant that interactional differences emerged which impacted on the shape of the email interview and the extent to which the email conversations with the academics were meaningful. Kivits (2005) has argued that the length of email responses is not a reflection of the intensity of the research relationship or the quality of data gathered. In the study, the academics experienced the online space in different ways. While the academics often wrote lengthy narratives about their experiences from the start of the email interviews, others answered more concisely or the emails were hastely written due to the pressures and demands in the academics' lives.

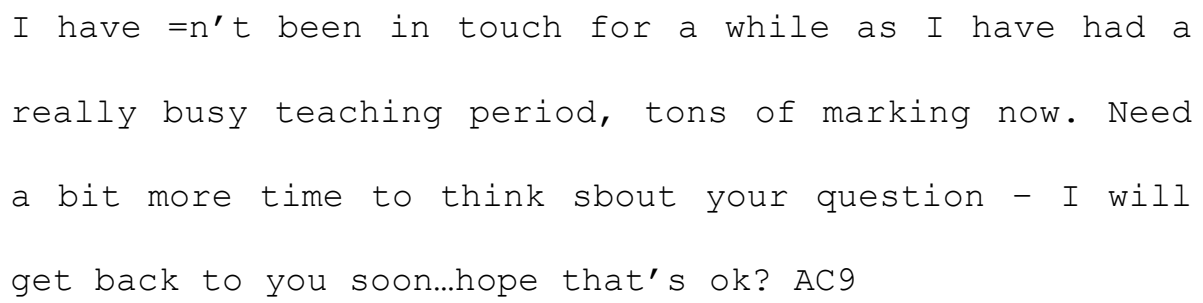

These exchanges reshaped the email interviews as the space of writing had a different and more reflective temporal spatial quality rather than the immediacy evident in conversational relational space (Max van Manen and Adams, 2013). In this sense, email offered the academics a mode of being and communication that "diluted the tensions, restrictions and expectations of the offline world" (Illingworth 2006 online, author's emphasis). Some academics took the opportunity email offered to reflect upon those aspects of their experiences and identities that might otherwise have remained invisible and unspoken, as well as provoke new questions about academic identity: 


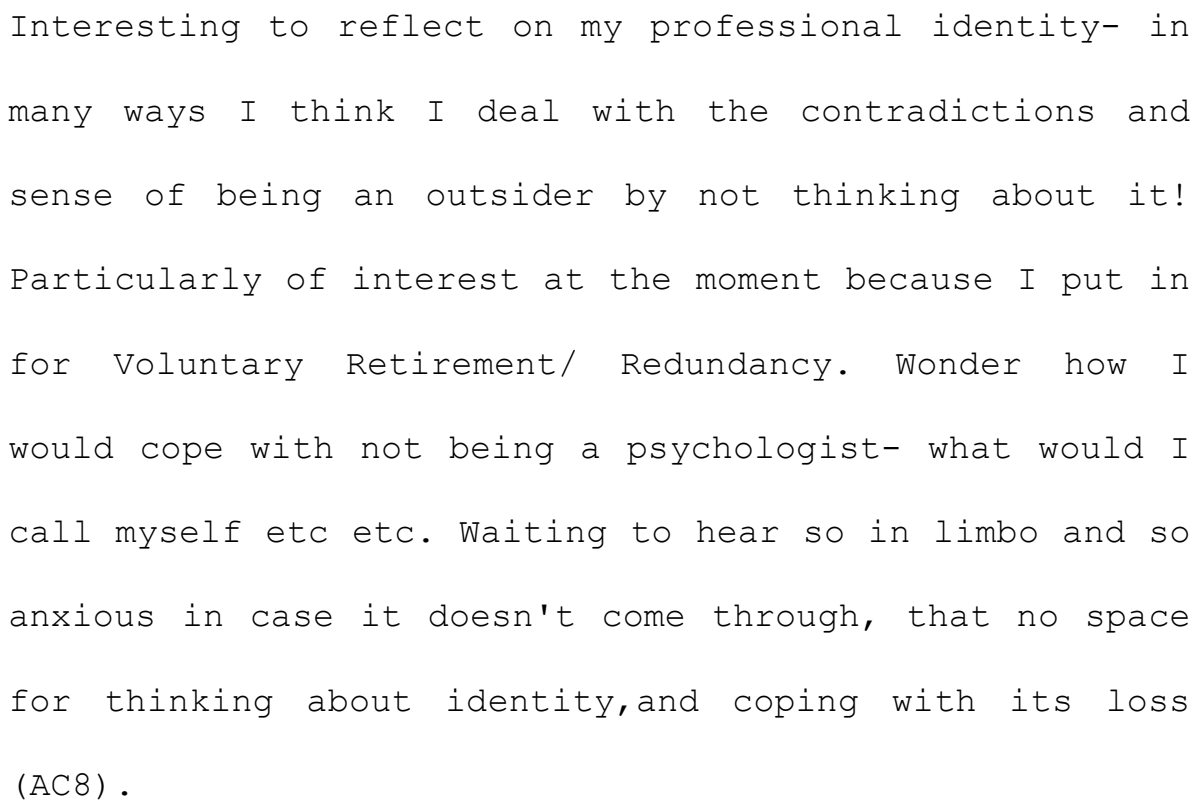

These reflections highlight how time-space compressions can also empower individuals to use email to, explore and make sense of their experiences. Critically, email communication remained intertwined with the academics' stories throughout, offering, as Markham (1998, p.125 original emphasis) suggests, a medium experienced "along a continuum from tool to place to way of being." The temporal dimension, reinforced by the asynchronous nature of email, created a social context in time and space in which they could explore changing self-perceptions and allowed for a thoughtful and personal form of conversation. A consequence of this temporality was that the email interviews took a long time to complete - interviews scheduled to take a matter of two or three weeks eventually extended in many cases over several months. Further, the academics' responses kept us alert with regard to how much we depended on their persistence and interest particularly as they were participating in an email interview which was 
interspersed with other activities, including online activities such as teaching and responding to multiple emails As the research questions were very much focused on their academic experiences and identities, this was less of a challenge. However, the process of sharing the same interview agenda was not so easy to achieve (see also Kivits, 2005). It did require patience on both the part of the researchers and participants to follow-up or seek clarification about the nuances of both the research questions and responses. The risk in this approach was that the academics often remained silent or absent, often for days or weeks. Such silences were at times disconcerting for the researchers because we were keen to maintain rapport, interaction and contact. However, these 'silences' 'absences' or 'lack of communication' were as much part of the research encounter as the construction of the narrative itself. The researchers therefore had to resist exploiting the virtual medium by overly prompting the academics to respond to the questions while at the same time achieving a balance between keeping them interested in the research and asking questions that were pertinent to their experiences. Emailing the academics to see if they were okay or whether they wanted to continue with the study would usually break the absence and confirm that they were still interested in participating. The academic narratives often indicated that these periods of silences/absences were being used to reflect on their academic identities:

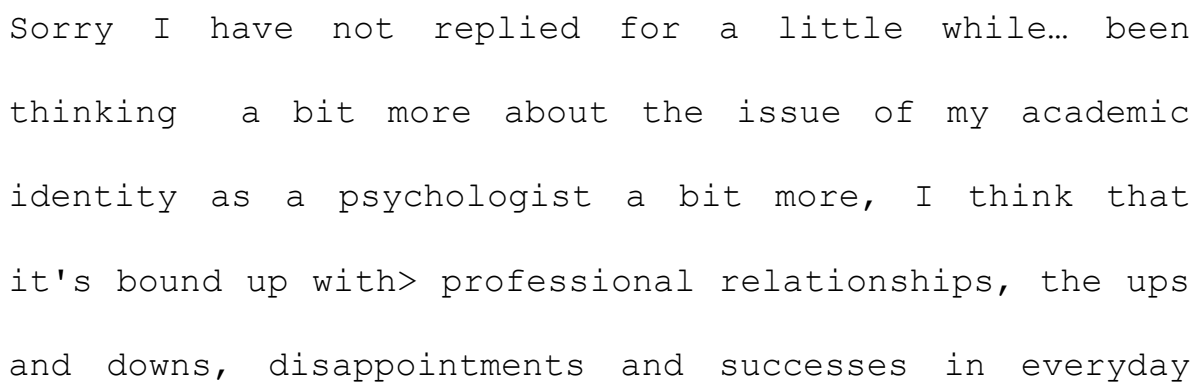




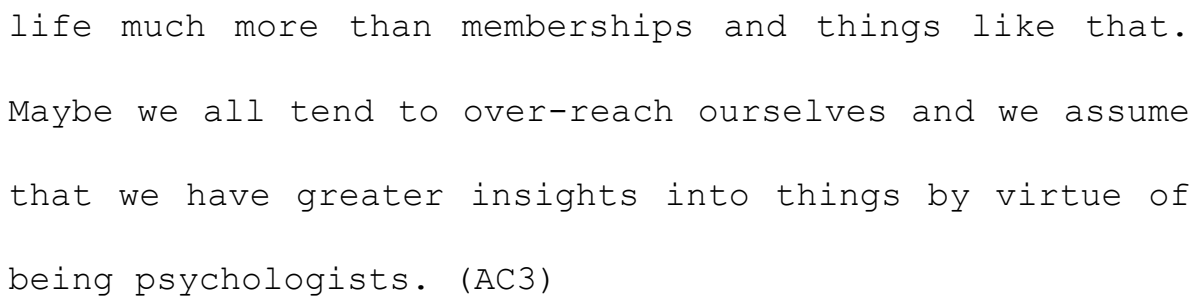

Carefully pondering their answers lead to lengthy delays between communications, yet enabled the academics to recall and better understand how they came to see themselves in their past and present careers as they picked up on issues that slipped temporarily out of view through the course of the interviews, and as they returned to earlier aspects of the narrative at their convenience (James 2007). By 'ignoring' the email questions, the Internet provided a space for the academics to talk as well as offer "both a space to reflect and a space not to talk" (Illingworth 2006, online).

\section{Using email to collect hybrid talk}

Some researchers have argued that communicating in the virtual world breaks the links between human experience, action and site that is thought to be so fundamental to ethnographic research (Burrell and Anderson, 2008; Beneito-Montagut 2011). However, people's online and offline worlds are deeply entangled in terms of space, time, place and embodiment. "Cyberspaces coexist with geographic spaces providing a new layer of virtual sites" (Kitchin, 1998, p. 403). So people, "make meaning of their experiences across online and offline spaces, producing identities without an exaggerated separation between these spaces" (Leander and McKim, 2003, p.219). For the study, the wider impact of this was that online, the research interviews were devoid of the normal social 
frameworks of face-to-face encounters between the researchers and participants, in which both interpret the social characteristics of the other, either verbally or non-verbally through gesture, tone of voice and facial expressions (James and Busher 2007; Irvine, Drew and Sainsbury, 2012). Researchers have argued that in the 'presentation of self', text makes invisible the bodily presence as well as outward acts of movement, posture, verbal and emotional expression that are important elements in determining how individuals see themselves and how they are perceived by others (Busher and James 2012). These non-verbal elements are a viewed as a key part of live communication, however, in the online context a layer of meaning is stripped out (Ison, 2010). Others have argued that while the 'lived body' may be invisible, during virtual interactions, mannered behaviours, pre-interpreted meanings and unstated assumptions are clearly visible during online conversations, influencing the nature of discourses and types of social interactions (Madge and O'Connor 2005). Indeed, the academics' virtual interactions were shaped by, and grounded in the social, bodily and cultural experiences of those taking part.

As noted earlier in the paper, the academics' narratives held a lot of residual attachments to their embodied experiences and lived practices of their working lives. Rather than using the virtual realm as a means of escaping the embodied self, they embraced it both as a practical information resource and as a medium of communication to explore and perform multiple identities. 


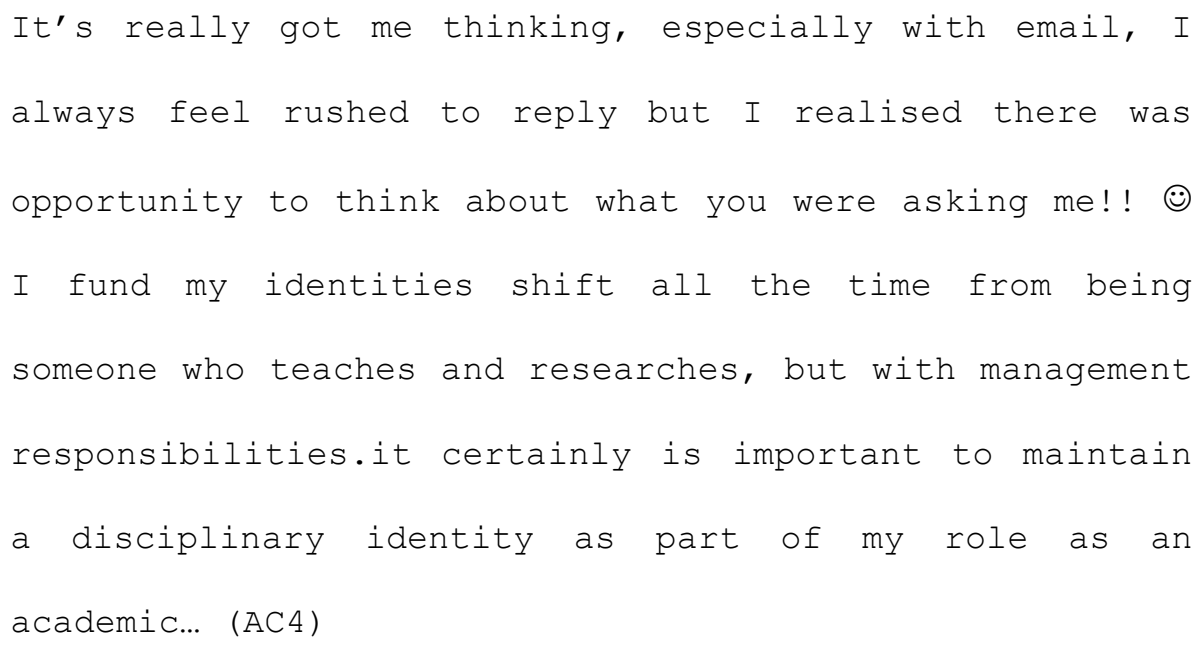

This approach allowed them to reflect deeper about their professional lives in a way which they might not have done and also helped them to develop a greater understanding of their identity construction in ways that were meaningful to them. These reflections highlight how research participants are not "dislocated, disembodied subjects, but people who are embedded in a variety of material relationships in particular places" (Morrow, Hawkins and Kern, 2014, p.11).

By interviewing the academics online, the researchers 'went to the source' meeting the academics in their own workplace and space rather than remotely. However relationships are not confined to cyberspace but can be performed and maintained in offline social spaces too (Tang, 2010). Furthermore, cyberspace is not an homogenous space; it consists of numerous websites and hybrid (online/offline) communities (James and Busher, 2013). The Internet enabled the construction of a specialized community where academics could identify with each other, across time and space, being both 
online and offline. In the study, the researchers and participants were connected both online and offline as we also had prior face-to-face knowledge of each other, as a consequence of our professional work. For example, following the email conversation with the participant about losing her academic identity (see above), both participant and researcher happened to be attending the same meeting and over coffee, the participant talked further about her experiences.. Later, when the email interview resumed, the researcher referred back to the discussion and probed some more by linking to issues that the participant had raised in the offline space:

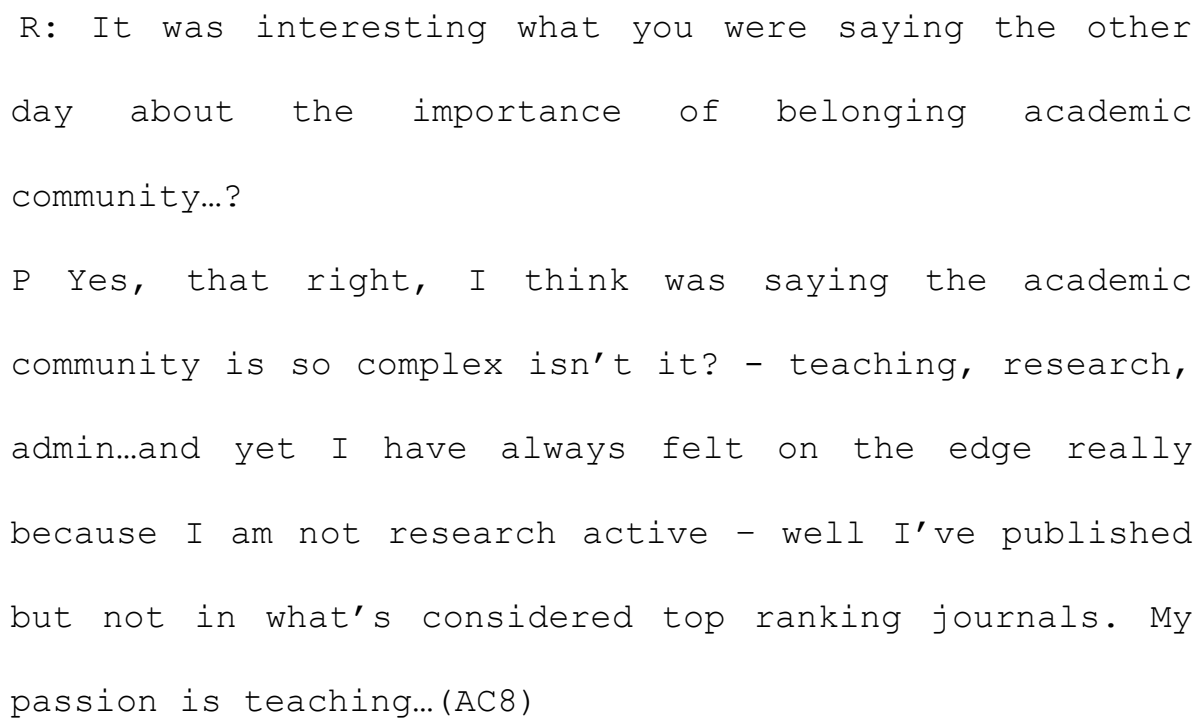

In this example, the researcher's relationship to the online narrative is part of a dialectical relationship between cyberspace and geographical space ( Morrow, Hawkins and Kern, 2014). The researcher's position at points during the email interviews connected between the virtual and real worlds. Further, cyberspace and online conversations did not occur outside the time / space of the academics' lives but rather 
were embedded in and integral to them. Time and space were therefore used "to insert the online world...into offline contexts, and vice versa" (Hine 2000 115). . The transition from a disembodied, anonymous and written interaction to an embodied and oral interaction with the participants introduced exciting opportunities for the research encounter. Our online communications had become the basis upon which offline face-toface contacts were further developed in terms of rapport and background knowledge which could be later used to authenticate the email interviews (Author and Author 2007). The move between online and offline interaction was useful in allowing the academic to elaborate on her experiences, adding further threads to the email interview. Through this process, the academic's narratives began to revisit and challenge past assumptions and expectations. Her voices indicated a gradual change and developing awareness, illustrating the process of active negotiation between previously held expectations and assumptions and the challenge of reflecting on her experiences.

As researchers, we discovered that by joining academics in the particular fieldsites that they lived in, meant joining them both online and offline, allowing the 'here and now' of everyday life in a particular space and time to interact ever more easily with the 'there and now' of the other in another time and space (Zhao 2006). In turn, such communications enabled us to actively engage and interact with the academics in both the online and offline spaces. Zhao (2006:4) carries this argument further, pointing out that the use of online communication does not just create new conditions and new forms of interaction, but, more importantly, it "transforms the spatial and temporal organization of social life," producing "new kinds of social relationships" and "new modes of 
exercising power" In other words, the rise of online communication leads to a social transformation that goes much deeper than a mere shift in ways of contacting others. This approach also echoes Boellstorff (2012) view that the virtual, or online distinction from the actual, or offline, is not blurred and should not be erased. The virtual and the actual are culturally organized and created and their meaning depends upon the context of social interaction.

\section{Email as empowering? Building collaborative relationships online}

Bowker and Tuffin (2004) suggest that email interviewing is potentially empowering for research participants because it allows them to control when, where and how to respond. This may be considered a frustrating experience for researchers conducting email interviews because of a sense of a lack of control over the temporal course of the interview. As the email interviews progressed, the academics began to take greater ownership of the processes of narrative construction by responding to the questions in unexpected ways and directions. In return, the researchers also were able to respond to the new directions of the participants' narratives by asking further questions about their texts rather than sticking to the original interview schedule (James and Busher 2006). We followed the participants' dialogue, prompting them from time to time to help the constructions of their narratives, but also intervening at some points with our own experiences to create a more open dialogue. In adopting this approach, the research setting and the contribution of the participants became more equal as they were in control of time and pace, fitting the interviews into the eftheveryday routines 2006).This allowed them to extend particular topics, qualify points and clarify their 
responses over time, restarting, erasing or editing their texts in the online context (Max von Manen and Adams, 2013). They, as much as the researchers, revisited data, controlled where the direction of discussion went, and influenced the nature of research processes.

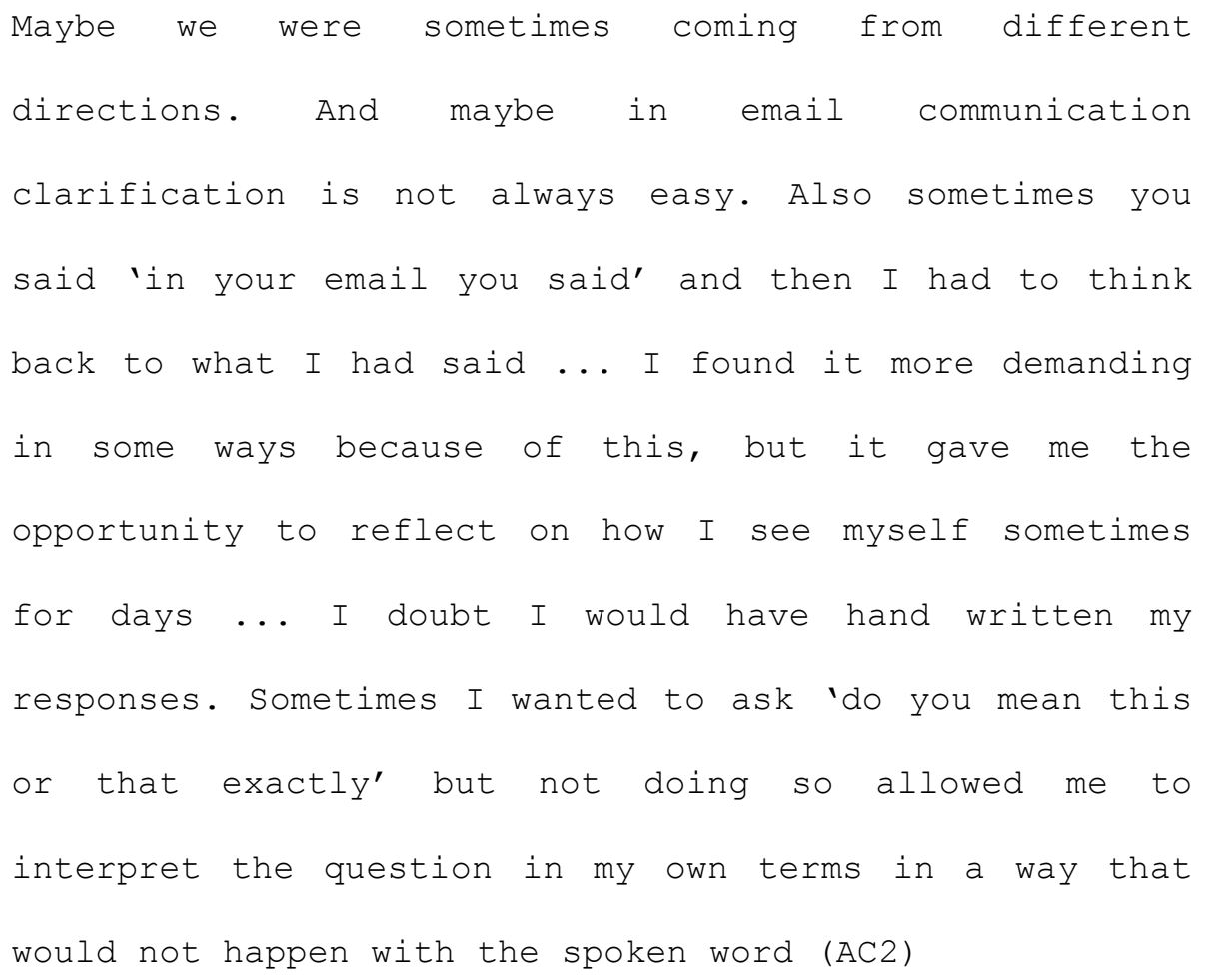

When the academics did raise issues and opinions, the researchers asked more questions to help our participants "reflect on a deeper level and get to the heart of the matter" (Russell and Bullock 1999 138). For example, in the research study, one participant repeated his concerns throughout our discussions, often returning to and clarifying earlier points made: Am I on the right track? Does that make 
sense? This approach also gave the researchers a second chance - to ask follow-up questions, clarify information and gather more detail. Within this process, participants' feelings and experiences were explored in-depth, and comments clarified to ensure that an accurate understanding of the academics' perspectives was developed. Further, the researchers incorporated their experiences and standpoints into the email interviews, by offering narratives about themselves. For example, one researcher found that following the narrative account of a specific email interview encouraged her to also self-disclose about her professional and personal experiences and identity construction (James 2007):

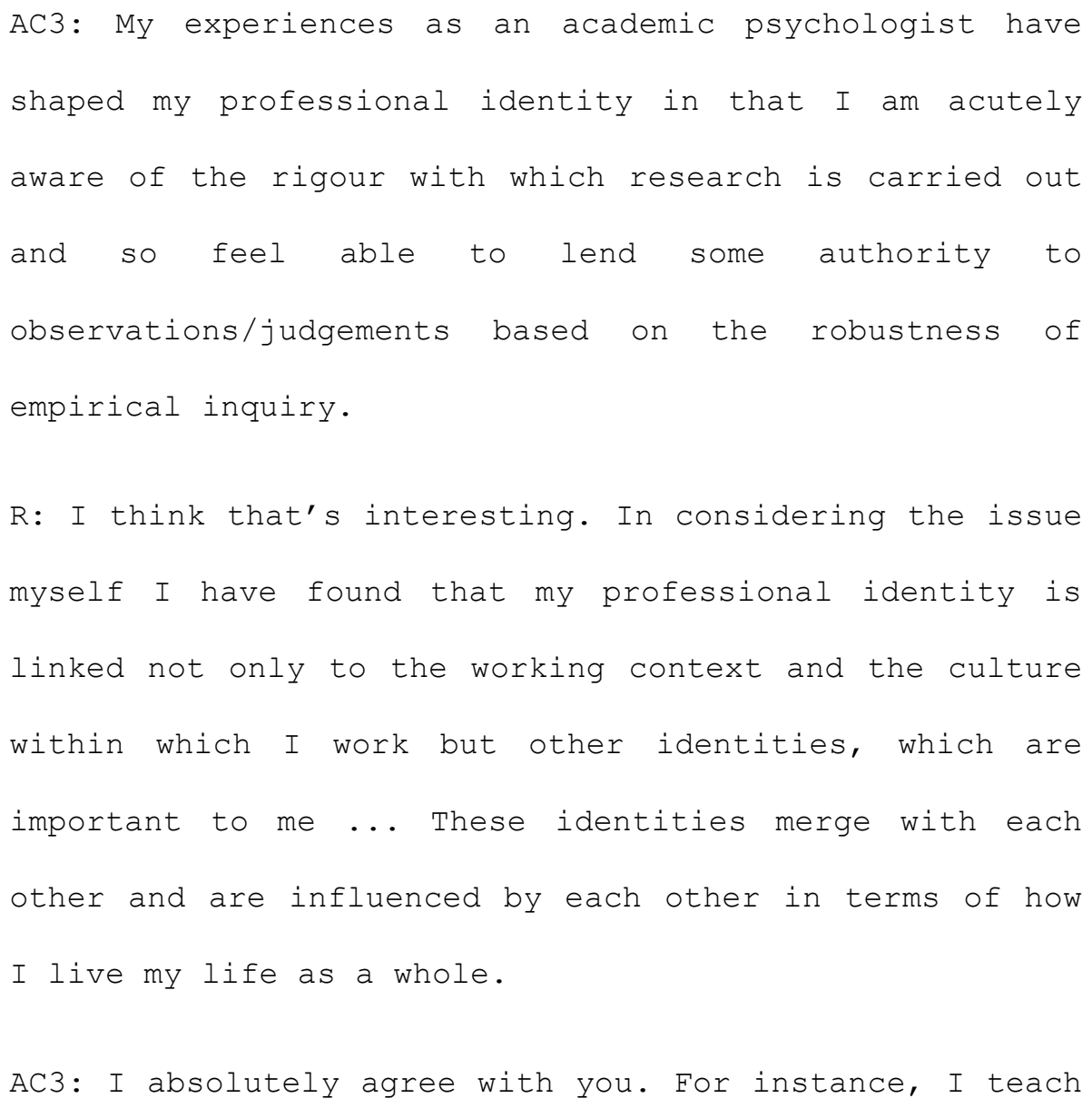




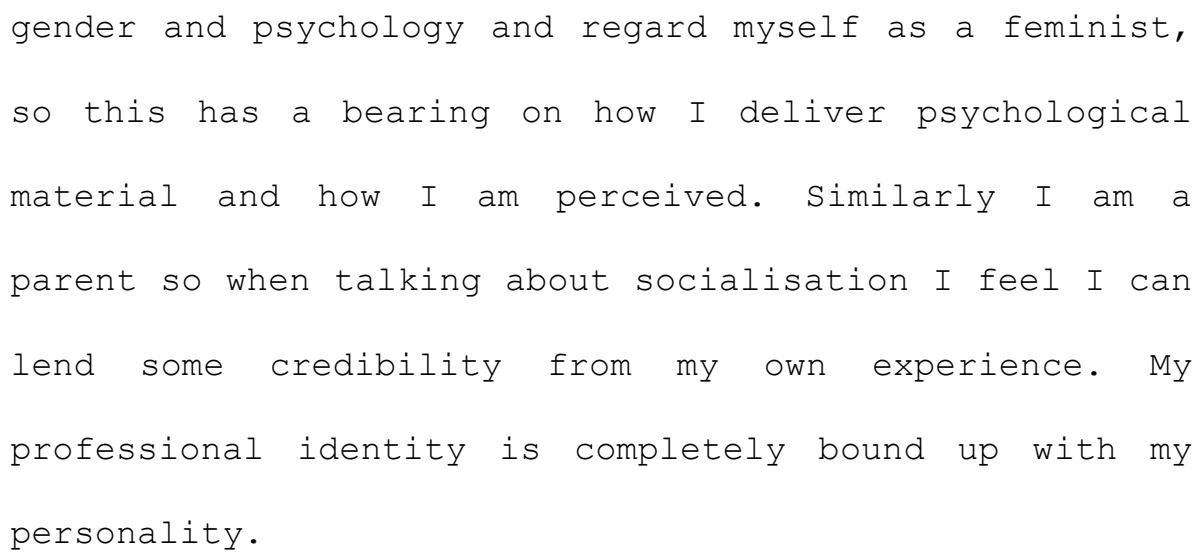

In this email conversation such disclosure, and the researcher's contribution and participation in the construction of the academics' narratives, shifted the position of the research relationship to one that was more democratic and dialectical (Seymour 2001). Both the researcher and participant were reflecting during a specific research encounter, legitimating both their roles as co-producers of the narratives within the research (Illingworth 2006 online). They were engaged interactionally and interpretatively irrespective of the power relationships between participants and researchers (Holstein and Gubrium 2004), as all parties were interested in the processes and outcomes of the research. This process temporarily helped to minimize the structural power hierarchies which at times were inherent, for example, through the researcher setting the research agenda, and asking the questions, It also involved the researcher in her own reflections, as well as the participants' ongoing reflections throughout the research encounter.

However participants are neither "passive" nor "powerless"” (Illingworth 2006, online). As the academics described how they saw themselves and made sense of their 
experiences, they made choices as to what to include in their narratives. In these reflexive moments, the participants took control of time and space to reflect on their discourses at a speed appropriate to their work-related contexts. The researchers found that the participants carefully considered their responses before they were 'uttered' giving them the feeling that they had control over their presentation of self. Such responses were just as credible as spontaneous ones, and for us, provided a more sophisticated understanding of academic identities constructed by the participants. In this sense the academics were not deprived of a sense of engagement in a human conversation, nor of a sense of power to present their own voice.

\section{Conclusion}

In this paper the researchers have argued that email allows both the researcher and the researched to participate in their own space, at their own pace and at the time of their choosing. In the study, the freedom offered by virtual communication in terms of time and space aided this process as the academics engaged in critical dialogue about their identities, in turn generating narratives that represented their constructed lives, thinking and reflections of their experiences, as well as "give meaning to their lives and capture these meanings in written, narrative ... forms" (Denzin and Lincoln 1994, 10). In this sense, the study illustrates the use of email "as a powerful medium of communication and reflection within the qualitative research encounter" (Illingworth 2006, online). It shows how email can provide an additional space that takes into account the way in which research participants' lives continue to take place, and in which they can reflect about their experiences in the midst of their experiences at a deeper level (Russell and Bullock 
1999). Responding to research questions as and when they choose, helps participants to engage in critical dialogue about their identities and develop narrative texts that are shaped more closely to their perspectives, and the meanings they construct for their lives.

Further, by allowing equal participation in one's own space and at one's own pace and time, email interviewing affords a more equal research relationship, in which participants are empowered to respond to the researcher's agenda in a considered way. In the study, this was achieved by responding to the varying directions the academics' narratives took by asking further questions about their texts rather than sticking to the structures of our original interview scripts. This approach diminishes the impact of the asymmetrical power relationships between participants and researchers that so often pervade qualitative research interviews, and gives participants the space to develop complex reflexive narratives about their professional selves. Yet, the potential for diffused power relations between researcher and participant online, emphasizing the potentially egalitarian nature of email and the genuineness of self- presentation, cannot be presumed (Kendall 1999). In the study, essential to this process was the way in which the academics spent time in reflective discourse in the narrative space, in which they had a degree of control and could respond when they liked, empowering them to take ownership of their narratives at a time and space convenient to them.

The research study has shown the 'embeddedness' of the Internet in people's every day lived experiences and the ways 'real life' is collaboratively and reflexively 
transformed and continuously re-interpreted in the digital space (Harricharan and Bhopal, 2014). Online and offline interactions are constituted and constructed together to sustain and transform the complex temporalities and spatialities of everyday life (Morrow, Hawkins and Kern, 2014, p. 9). The email narratives also highlighted how virtual and real worlds are shaped by the online/offline positionalities of both the researchers and participants. Cyberspace may at times operate as a place to 'be' (Markham, 1998), but communication within remains intimately connected to the offline world and, within this study, was a critical component of the qualitative research encounter. The offline encounters with the academics allowed the researchers to refer to issues that sometimes remained undeveloped in our online interactions. In the press of their busy lives this proved to be a useful process, highlighting how it is no longer useful to differentiate between the real and the virtual in everyday-life social interactions (Benito-Montagut 2011). As Markham $(2004,147)$ notes, "methodologically we should not ignore this feature because as interaction constructs and reflects the shape of the phenomena being studied, interaction also delineates the being doing the research in the field." Sometimes the academics performed vulnerable identities, as they were thinking critically about who they were, which sometimes led to "identity struggles" (Lebesco 2004, 73) as they grappled with the tensions and negotiations that existed in shaping their identities. This also reiterated how "the spaces of interaction might be differently configured and differently experienced, but they do not lose all reference to offline realities" (Hine 2000, 144).

To sum up, email is a useful site for rich and sustained interactions and a useful tool to capture the complexity of social interaction online. As this research study on 
academic identity demonstrates, using email for interviewing provides a means by which individuals can take part in research that is important to their lives which they might not have been able to do had the researchers had to rely on face-to-face interviews. It is not about creating a research design that is most convenient for the researcher. In the study, the very purpose of using email interviews was that the "absence of a proper locus [provided] the academics with a space to explore the aspects of their experiences and identities that otherwise remained initerable" (Eichorn 2001, 572). In this sense, the research encounter and the virtual space as the context of communication can be used as a site for participants and researchers to interact online and offline, and to reflect on experience, and for researchers to study and better understand the multi-sited nature of their lives.

\section{References}

Adams, A. and Thompson, T.L. 2011. Interviewing objects. Including educational technologies as qualitative research participants. International Journal of Qualitative Studies in Education 24, no. 6: 733-750

Beneito-Montagut, R. 2011 Ethnography goes online: towards a user-centred methodology to research interpersonal communication on the Internet. Qualitative Research 11, no.6: 716-735.

Boellstorff, T. (2012) Rethinking digital ethnography In Digital Anthropology, eds.H.A. Horst and D. Miller, 39-60. London: Berg. 
Bowker, N. and K. Tuffin 2004. Using the online medium for discursive research about people with disabilities. Social Science Computer Review 22, no.2: 228-41.

Burrell, J. and Anderson, K. 2008. I have great desires to look beyond my world: trajectories of information and communication technology use among Ghanaians living abroad. New Media Society 10, no. 2: 203-224.

Busher, H. and James, N. (2012) Qualitative interviewing in cyberspace. In Handbook of qualitative research, ed. S. Delamont, 223-240. Cheltenham, Edward Elgar.

Burns, E. 2010. Developing email interview practices in qualitative research, Sociological Research Online 15, no. 4: Retrieved from $<$ http://www.socresonline.org.uk/15/4/8.html> 10.5153/sro.2232

Clandinin, D.J. and Connelly, F.M. 2000. Narrative inquiry: Experience and story in qualitative research, San Fransciso: Jossey Bass.

Czarniawska, B. 2004. Narratives in social science research, London, Sage.

Davies, J. 2011. Discourse and computer-medicated communication. In Continuum Companion to Discourse Analysis, eds Brian Paltridge and Ken Hyland, 228242. London: Continuum. 
Denzin, N.K. 2001. The reflexive interview and a performative social science. Qualitative Research 1, no. 1: 23-46.

Denzin, N. K. \& Lincoln, Y.S. (1994) Introduction: Entering the field of qualitative research. In Handbook of qualitative research, eds. N. K. Denzin and Y. S. Lincoln, 10-15. London: Sage.

Eichorn, K. 2001. Sites unseen: ethnographic research in a textual community. Qualitative Studies in Education, 14, no. 4: 565-578.

Hardey, M. 2004. Digital life stories: Auto/biography in the information age. Auto/Biography, 12, no. 1: 183-200.

Harvey, D. (1989) The Conditions of Postmodernity, An Enquiry into the Origins of Cultural Change, Oxford: Blackwell.

Hallet, R. and Barber, K. 2013 Ethnographic research in a cyber era. Journal of Contemporary Ethnography, 12, no.8:1-25

Harricharan, M. and Bhopal, K. (2014) Using blogs in qualitative educational research: an exploration of method, International Journal of Research \& Method in Education, 37, no.3: 324-343, 
Hasim, Z., R. De Luca, and B. Bell. 2011. Issues and challenges of using web blogs as a medium for research communication. Waikato Journal of Education 16 , no. 1: $143-150$

Henkel, M. 2000 Academic identities. Policy change in higher education, London and Philadelphia, Jessica Kingsley Publishers.

Hinchcliffe, V. and Gavin, H. 2008. Internet mediated research: a critical reflection upon the practice of using instant messenger for higher educational research interviewing. Psychology and Society, 1, no.1: 91-104.

Hine, C. 2000. Virtual ethnography, London: Sage.

Irvine, A., Drew, P., and Sainsbury, R. (2012) 'Am I not answering your questions properly,' Clarification, adequacy and responsiveness in semi-structured telephone and face-to-face interviews, Qualitative Research, 13, no.1: 87-106.

Illingworth, N. 2006. Content, context, reflexivity and the qualitative research encounter: Telling stories in the virtual realm, Sociological Research Online, 11, no. 1: Retrieved from <http://www.socresonline.org.uk/11/1/illingworth.html>. 
Ison, N. 2009. Having their say: email interviews for research data collection with people who have verbal communication impairment, International Journal of Social Research Methodology, 12, no.2: 161-172

James,N. 2003. Teacher professionalism, teacher identity: How do I see myself? Unpublished Doctorate of Education Thesis, University of Leicester, School of Education, July 2003.

James, N. 2007. The use of email interviewing as a qualitative method of inquiry in educational research, British Educational Research Journal, 33, no. 6: 963-976.

James N. and Busher, H. (2006) Credibility, authenticity and voice: dilemmas in webbased interviewing. Qualitative Research Journal, 6, no. 3: 403-420.

James N. and Busher, H. 2007. Ethical issues in online educational research: Protecting privacy, establishing authenticity in email interviewing. International Journal of Research \& Method in Education, 30, no: 1, 101-113.

James, N. and Busher, H . 2009. Online interviewing, London: Sage. 
Joinson, A.N. 2001. Self-disclosure in computer-mediated communication: the role of self-awareness and visual anonymity. European Journal of Social Psychology, 31, no. 2: 177-92.

Kitchin, R. M. 1998. Towards geographies of cyberspace, Progress in Human Geography 22, no.3: 385-406.

Kivits, J. 2005. Online interviewing and the research relationshop. In Virtual methods: Issues in social research on the Internet, ed. C. Hines, 35-51. Oxford: Berg.

Lebesco, K. 2004. Managing visibility, intimacy, and focus in online critical ethnography. In Online social research: Methods, issues and ethics, eds. M.D. Johns, S.L.S. Chen, and G. J. Hall, 63-80. Oxford: Peter Lang Publishing.

Leander, K. M., and K. K. McKim. 2003. Tracing the everyday 'sittings' of adolescents on the Internet: A strategic adaptation of ethnography across online and offline spaces, Communication and Information 3, no.2: 211-240.

Lee, H., and Liebenau, J. (2000). Time and the Internet at the turn of the millennium. Time and Society, 9,no 1: 43-56. 
McCoyd , J. L. M. and Kerson, T. S. 2006. Conducting intensive interviews using email: A serendipitous comparative opportunity. Qualitative Social Work, 5, no. 3: 389421.

Madge, C. and O'Connor, H. 2005. Mothers in the making? Exploring notations of liminality in hybrid cyber/space. Transactions of the Institute of British Geographers, 30, no. 1: 83- 97.

Mann, C. and Stewart, F. 2000. Internet communication and qualitative research: A hand- book for researching online. London: Sage.

Markham, A.N. 1998. Life online: researching real experience in virtual space. Walnut Creek, CA: AltaMira Press.

Markham, A.N. 2004. Representation in online ethnography. In Online social research: Methods, issues and ethics, eds. M.D. Johns, S.L.S. Chen, and G. J. Hall, 141-156 Oxford: Peter Lang Publishing.

Massey, D. (1994) Space, Place and Gender . Cambridge: Polity Press.

Meho, I. 2006. E-Mail interviewing in qualitative research: A methodological discussion. Journal of the American Society for Information Science and Technology, 57, no. 10: $1284-1295$ 
Morrow, O., Hawkins, R. and Kern, L. (2014) Feminist research in online spaces, Gender, Place and Culture: A Journal of Feminist Geography, 10, no 1:2-18.

Murthy, D. 2008. Digital Ethnography: An examination of the use of new technologies for social research, Sociology, 42, no. 5: 837-855.

Orgad, S. 2005. From online to offline and back: moving from online to offline relationships with research participants. In: Virtual methods: Issues in social research on the Internet, ed. C. Hines, 51-66. Oxford: Berg.

Tsatou, P. 2009. Reconceptualising time and space in the era of electronic media and communications, PLATFORM: Journal of Media and Communication, 3, no. 1: 11-32.

Russell, T. and Bullock, S. 1999. Discovering our professional knowledge as teachers: Critical dialogues about learning from experience. In Researching methodologies and practices for understanding pedagogy, ed. J. Loughran, 132-152. New York: The Falmer Press.

Seymour, W.S. 2001. In the flesh or online? Exploring qualitative research methodologies, Qualitative Research, 1, no. 2: 147-168.

Tang, L. (2010) Development of online friendship in different social spaces, Information, Communication \& Society, 13, no.4, 614-633. 
Taylor, C. 1989. Sources of the self. MA Harvard University Press.

Thrift, N. (1994) Inhuman geographies: Landscapes of speed, light and power. In Cloke,Paul; Doel, Marcus; Matless, David; Phillips, Martin and Thrift, Nigel eds. Writing the Rural: Five Cultural Geographies, $\quad$ London: Paul Chapman Publishing.

Van Manen, M. and Adams, C. (2009) The phenomenology of space in writing online, Educational Theory and Philosophy, 41, no.1: 10-21.

Zhao, S. 2006 The internet and the transformation of the reality of everyday life: Toward a New Analytic Stance in Sociology. Sociological Inquiry 76, no. 4: 458-474. 